\title{
INTERACTION OF ACETATE, GLUCOSE AND GROWTH CONDITIONS ON GLYCONEOGENESIS AND ISOCITRATE LYASE ACTIVITY IN TETRAHYMENA*
}

\author{
MICHAEL R. LEVY \\ Department of Zoology, University of Michigan, \\ Ann Arbor, Michigan 48104, U.S.A.
}

(Received 14 November 1966)

\begin{abstract}
Incubation of shaken cultures for $3 \mathrm{hr}$ with acetate had little effect on the level of isocitrate lyase or the capacity for glyconeogenesis.

2. Maintenance of cultures under static conditions for the same period led to an eight to tenfold increase in the enzyme and to a greatly enhanced ability to convert acetate to glycogen.

3. Glucose prevented most of the increase in enzyme and led to a complete loss of the capacity for glyconeogenesis.

4. Starved cells from non-shaken suspensions developed an increased capacity for glyconeogenesis, and the presence of acetate further increased this capacity.

5. Cells from suspensions shaken with acetate had a much lower capacity.

6. It is concluded that in Tetrahymena growth conditions are much more important than acetate in the regulation of glyconeogenesis and the synthesis of isocitrate lyase.
\end{abstract}

\section{INTRODUCTION}

IN Tetrahymena pyriformis, the glyoxylate bypass of the tricarboxylic acid cycle is involved in the conversion of lipids to carbohydrate (Hogg \& Kornberg, 1963). In the GL strain of this organism, synthesis of isocitrate lyase, the key enzyme of this pathway, and an increased capacity for glyconeogenesis can be induced by transferring well-shaken, log-phase cultures of this ciliate to static conditions (Levy \& Scherbaum, 1965a, b). Within $3 \mathrm{hr}$ there is approximately a doubling in the capacity for glyconeogenesis from acetate and in the specific activity of isocitrate lyase. In the $\mathrm{E}$ strain, a six to tenfold increase in the specific activity of isocitrate lyase occurs (Levy, 1967). Similar results can be obtained with cells in nonnutrient medium.

It has been reported that the presence of acetate in the growth medium also leads to elevated levels of isocitrate lyase and to the ability to convert lipids to glycogen in this organism (Hogg \& Kornberg, 1963). When glucose and acetate were present together, induction of the enzyme took place, but cells were incapable of converting lipids to glycogen.

* This investigation was supported by U.S.P.H.S. Training Grant 5T-1-GM-989 and by Research Grant AI 01416-14 (to A. M. Elliott), National Institute of Allergy and Infectious Diseases. 
Because the latter experiments were done with statically grown cultures, it became of interest to determine if the results were due to the presence of acetate or to the growth conditions. The present results indicate that growth conditions are much more important than acetate in regulating glyconeogenesis and isocitrate lyase synthesis in Tetrahymena. A preliminary report of this work has appeared (Levy, 1966).

\section{METHODS}

Cultures of Tetrahymena pyriformis $\mathrm{E}$ were grown in a medium containing proteose peptone, liver fraction and $\mathrm{K}_{2} \mathrm{HPO}_{4}$, as described previously (Levy \& Scherbaum, 1965a). Activation of glyconeogenesis was accomplished by transferring well-shaken, log-phase cultures, or washed cells from such cultures, to static conditions, with concomitant reduction of the surface/volume ratio, as described elsewhere (Levy \& Scherbaum, 1965a). Glyconeogenesis was tested by washing the cells and shaking duplicate $2-\mathrm{ml}$ aliquots for $1 \mathrm{hr}$ in inorganic medium containing about $0.05 \mu \mathrm{c}$ of sodium acetate-2- ${ }^{14} \mathrm{C}$ (specific activity $23 \mathrm{mc} / \mathrm{mmole}$ ), with or without $2.5 \mathrm{mg}$ sodium acetate. Rates are expressed as $\mu$ moles glucose formed. $\mathrm{hr}^{-1} \mathrm{mg}^{-1}$ protein. Procedures for determination of glycogen, protein, isocitrate lyase activity and radioactivity have been given elsewhere (Levy \& Scherbaum, 1965a, b).

\section{RESULTS}

In the first experiment, shaken portions of log-phase peptone cultures were treated in one of the following ways: (1) harvested immediately ( 0 -hr control); (2) shaken $3 \mathrm{hr}$ (3-hr control); (3) shaken $3 \mathrm{hr}$ with $1 \mathrm{mg} / \mathrm{ml}$ sodium acetate; (4) shaken $3 \mathrm{hr}$ with $1 \mathrm{mg} / \mathrm{ml}$ glucose; (5) static, $3.5 \mathrm{hr}$; (6) static, $3.5 \mathrm{hr}$ + acetate; (7) static, $3.5 \mathrm{hr}+$ glucose; (8) static, $3.5 \mathrm{hr}+$ glucose and acetate. Cells were then harvested, washed and suspended in inorganic medium. Glyconeogenesis was tested as described in the Methods section.

Figure 1 shows the cellular glycogen content at the end of the treatments, and the changes that occurred during the subsequent 1-hr incubation period. Rates of glyconeogenesis are summarized in Fig. 2. Cells from the shaken control cultures or from shaken cultures containing acetate had relatively low glycogen levels. When washed suspensions of these cells were tested for glyconeogenesis, the maximum rates were $0.078,0.13$ and $0.17 \mu$ moles glucose formed. $\mathrm{hr}^{-1} \mathrm{mg}^{-1}$ protein, respectively, for the 0 - and $3-\mathrm{hr}$ controls, and for the cells shaken with acetate. In each of these samples, the endogenous rate was somewhat higher than the rate obtained in the presence of acetate. Thus, the addition of acetate to the culture medium at best led to only a slight increase in the capacity for glyconeogenesis. Cells shaken for $3 \mathrm{hr}$ with glucose had a high glycogen content (21 per cent of cell protein) but were unable to convert acetate to glycogen.

Cells from cultures maintained under static conditions in the presence or absence of acetate contained more glycogen and, when washed and shaken with acetate, formed glycogen at greater rates than did cells from shaken cultures. Thus, the rates of glyconeogenesis in cells from static cultures lacking and containing acetate were 0.46 and 0.31 , respectively. (These rates, as well as those of the controls, are somewhat higher than those usually obtained.) The addition of glucose to the 


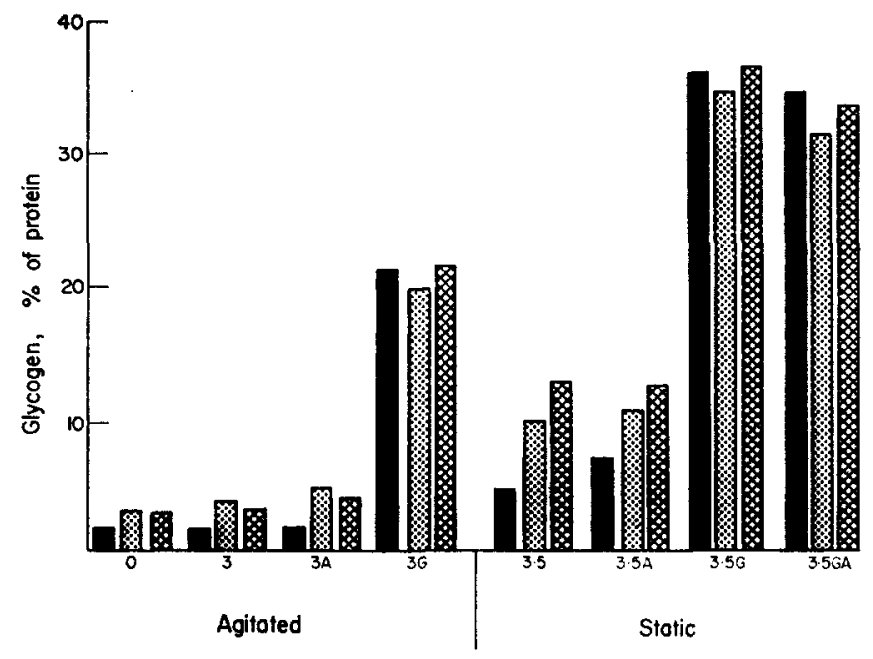

FIG. 1. Effects of substrate and growth conditions on glycogen content and glyconeogenic capacity. Log-phase cultures were treated as described in the text. At the time indicated, cells were collected, washed and shaken for $1 \mathrm{hr}$ with tracer or substrate levels of sodium acetate. $G=$ glucose, $A=$ acetate. Solid bars = glycogen content immediately after washing; stippled bars = content after 1-hr incubation with tracer quantities of acetate (endogenous rate); crosshatched bars $=$ content after $1-\mathrm{hr}$ incubation with tracer $+2.5 \mathrm{mg}$ sodium acetate.

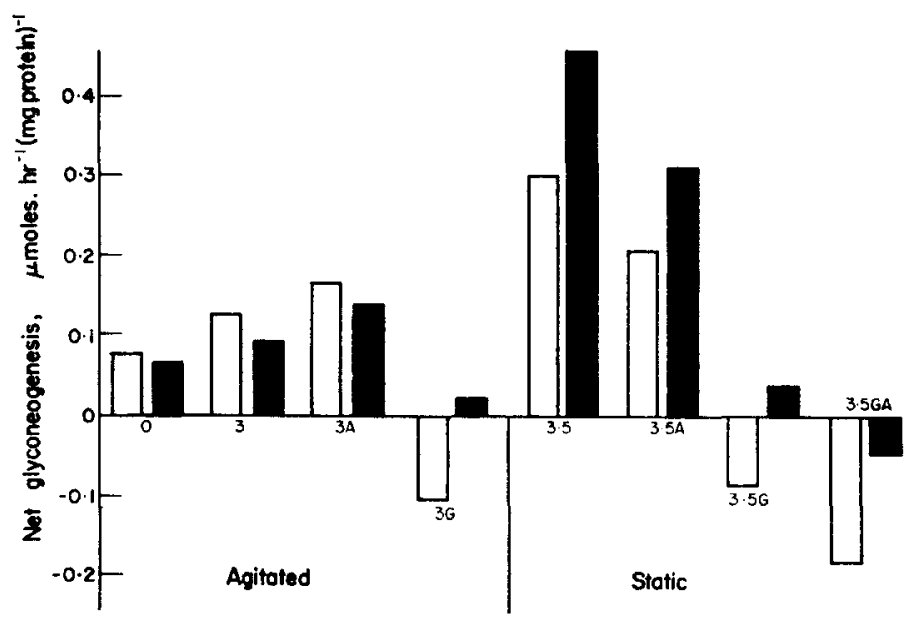

Fig. 2. Rates of glyconeogenesis. Rates compiled from the data of Fig. 1. Open bars = endogenous rates; solid bars = rates in presence of acetate. 
static cultures led to a large increase in cellular glycogen content (34 per cent of cell protein), but prevented the development of glyconeogenic capacity. Addition of acetate together with the glucose did not relieve this inhibition.

Incorporation of labelled acetate into glycogen (Fig. 3) paralleled the results on glyconeogenesis. Cells from shaken, acetate-containing cultures converted substrate quantities of acetate- $2-{ }^{14} \mathrm{C}$ to glycogen at only a slightly greater rate than cells
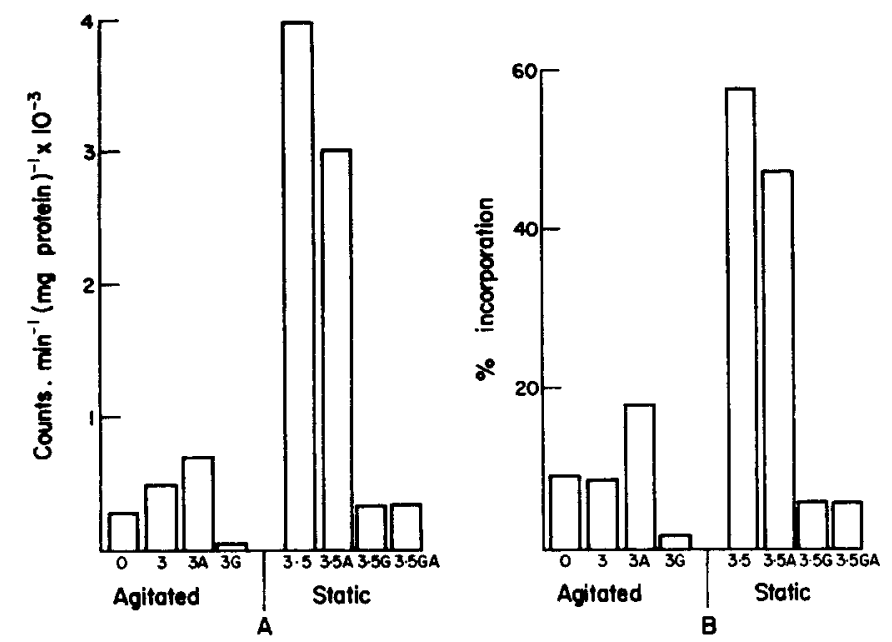

FIG. 3. Incorporation of acetate-2-14 $\mathrm{C}$ into glycogen. (A) Uptake in the presence of $2.5 \mathrm{mg}$ sodium acetate. (B) Uptake in the presence of tracer only.

from control cultures. However, the rate in cells that had been maintained under static conditions was about eight times that of the controls. When acetate was present at tracer levels, similar results were obtained. Cells from static cultures incorporated almost 60 per cent of the added isotope into glycogen.

Samples of these cells were also tested for isocitrate lyase activity (Fig. 4). The specific activity of this enzyme in cells from cultures shaken with acetate was 67 per cent higher than in cells from shaken controls. In contrast, cells from static cultures showed an increase of 670 per cent over the 3-hr controls, and of 1000 per cent over the $0-\mathrm{hr}$ controls. The increase in cells from static cultures containing acetate was somewhat less in this experiment, but usually was about the same as in the static controls. In a separate experiment, the acetate concentration in a shaken culture was increased fivefold without further effect on the level of isocitrate lyase.

The presence of glucose in static cultures largely prevented the increase in the specific activity of isocitrate lyase. However, it is of interest that the final level was still higher than in cells shaken with acetate. Thus, cells from static cultures containing a repressor of isocitrate lyase synthesis had a higher specific activity of this enzyme than did cells shaken with a substrate that often acts as an inducer. 
Isocitrate lyase activity in cells shaken with glucose was essentially the same as that of the controls.

Glyconeogenesis and isocitrate lyase activity can also be induced in starved cells, if these are maintained under static conditions. However, the increase in the amount of enzyme is reduced. It might be expected that starvation would lower the level of exogenous nutrients that act as a source of repressors of isocitrate lyase synthesis [although intracellular breakdown products do become abundant (Koroly \& Conner, 1966; Levy \& Elliott, unpublished data)]. To test the effects of acetate on starved cells, Tetrahymena from growing cultures were harvested, washed and preincubated by shaking for $3 \mathrm{hr}$ in inorganic medium. Portions of

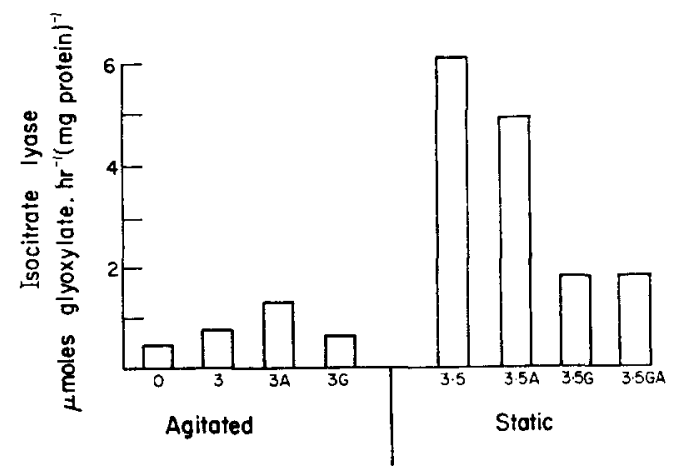

FIg. 4. Specific activity of isocitrate lyase. See legend for Fig. 1.

suspension were then either shaken for an additional $3 \mathrm{hr}$ or maintained under static conditions for the same period, in either case, in the presence or absence of $1 \mathrm{mg} / \mathrm{ml}$ sodium acetate. At 0 or $3 \mathrm{hr}$ after the preincubation, cells were collected, washed and tested for glyconeogenesis. Results are shown in Table 1.

Cells shaken with acetate for $3 \mathrm{hr}$ could form glycogen at somewhat higher rates than could the $0-\mathrm{hr}$ controls, but not as rapidly as cells from static suspensions lacking acetate. The presence of acetate in static suspensions did, however, lead to an even greater increase in the capacity for glyconeogenesis. In general, cells from such suspensions could form glycogen at twice the rate as cells from static suspensions lacking acetate. The differences in glyconeogenesis between shaken and static suspensions are reflected in the uptake of labelled acetate into glycogen. Isocitrate lyase activity doubled in cells shaken with acetate and increased to a slightly greater extent in the static samples.

\section{DISCUSSION}

In many microorganisms, high levels of isocitrate lyase are found in cells growing on acetate or acetate precursors (Kornberg \& Elsden, 1961). Acetate is believed to lead to the removal of an intracellular repressor of isocitrate lyase synthesis, probably phosphoenolpyruvate (Kornberg, 1964). However, acetate may 
MrchaEd, R. LeVY

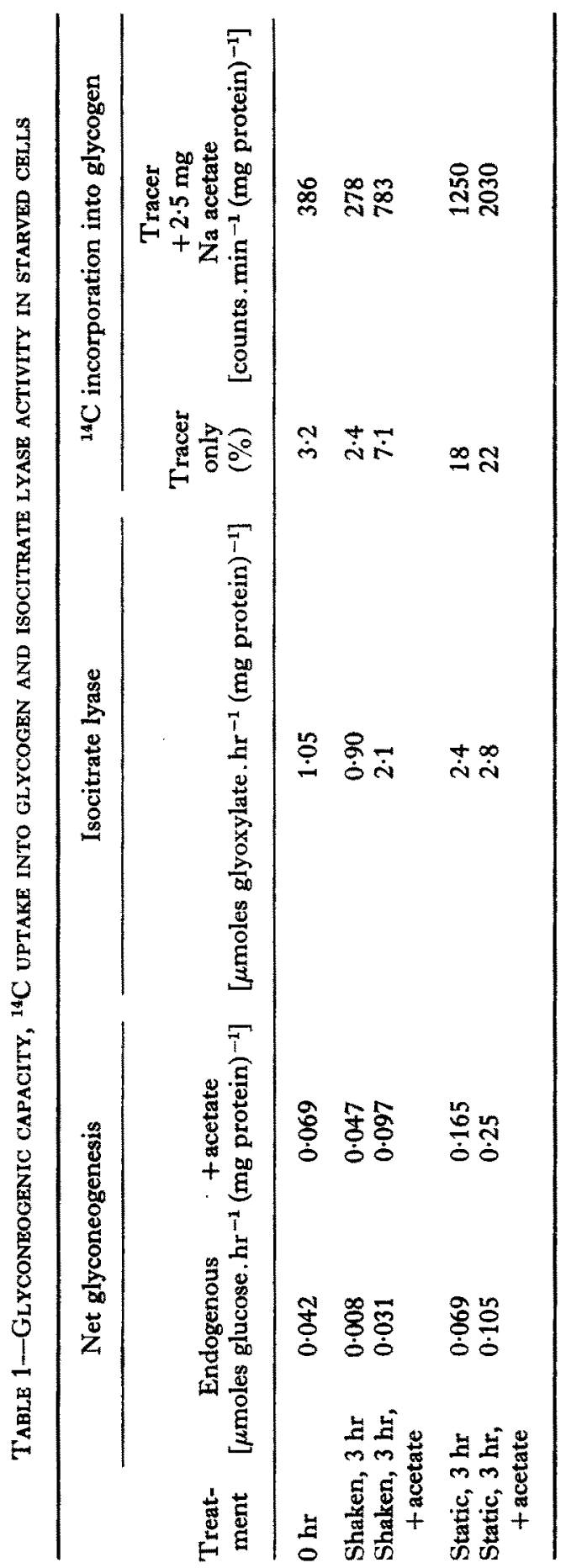


have little effect on the level of this enzyme in cells growing well on other precursors (Kornberg, 1963).

Various workers have shown that the level of isocitrate lyase may be dependent upon the growth stage of the culture. In Rhizopus nigricans, the specific activity increased with culture age in cells grown on casein hydrolysate, reaching a peak as the culture reached the stationary growth phase (Wegener \& Romano, 1964). Similarly, Megraw \& Beers (1964) concluded that in Bacillus cereus, isocitrate lyase synthesis, regardless of carbon source, was a function of growth. The highest levels of this enzyme were always observed at the beginning of sporogenesis, and the peak was much higher in cells grown on glutamate or yeast extract than in cells grown on glucose or acetate.

In the present experiments, cells from shaken peptone cultures had low levels of isocitrate lyase, and there was only a slight increase after a 3-hr incubation with acetate. However, if cultures were transferred to static conditions for the same period, an eight to tenfold increase occurred, and there was no further increase if acetate was present. Since the nutrients available to the cells were the same, different metabolic pathways must predominate in shaken and static cultures. Presumably, in the static cells the removal of an intracellular repressor permits isocitrate lyase synthesis to proceed, and it seems clear that changes in culture conditions are much more effective in removal of the inhibition than is acetate. These conditions also lead to an increase in the activity of the existing isocitrate lyase, since activation of glyconeogenesis is not dependent upon synthesis of this enzyme (Levy, 1967). The effects of acetate and growth conditions on glyconeogenesis paralleled the effects on isocitrate lyase synthesis. Addition of acetate to shaken cultures led to only a slight increase in the capacity to convert acetate to glycogen, whereas cells that had been kept under static conditions could do so at high rates.

Some of the results presented here are at variance with those of Hogg \& Kornberg (1963). Using statically grown cells, these workers reported that the specific activity of isocitrate lyase was fifteen to twenty times greater in cells from peptone-acetate cultures than in cells grown on peptone alone. However, the values reported were 0.055 for the constitutive, and 0.85 for the induced cells. The latter figure is about the same as that found in the uninduced cells in the present experiments. It was also reported that glucose did not prevent the induction of isocitrate lyase by acetate. In the present experiments, glucose prevented most of the increase that occurred. It is possible that the greater enzyme levels found here are due to the presence of liver fraction in the medium, although fourfold increases in the specific activity of isocitrate lyase have been observed when freshly harvested cells are kept under static conditions for $3 \mathrm{hr}$ in inorganic medium. The reasons for the differences in response are not clear. It is possible that at the time of harvesting, there were variations in the growth stage and cell population in the various media used by Hogg and Kornberg.

The experiments on starved cells show that under certain conditions, acetate can lead to an increase in the capacity for glyconeogenesis. Thus, while cells taken 
from static suspensions could convert acetate to glycogen at accelerated rates, the presence of acetate during the activation period usually led to a further doubling of the rate.

The mechanisms leading to the induction of isocitrate lyase and the activation of glyconeogenesis in Tetrahymena will have to await clarification of the metabolic changes that occur when cells are transferred to static conditions. Conditions are chosen that severely limit the availability of oxygen to the organism and induce the stationary growth phase (Levy \& Scherbaum, 1965a). Most of the same changes occur if cells are shaken under 1 per cent $\mathrm{O}_{2}$ for several hours. Since similar qualitative changes are obtained if cells are transferred to static conditions in a rich medium or in inorganic medium, even after a starvation period, it would seem that in this organism, the amount of isocitrate lyase and the capacity to convert acetate to glycogen are controlled primarily by the growth conditions.

\section{REFERENCES}

HoGG J. F. \& KorNBERG H. L. (1963) The metabolism of $\mathrm{C}_{2}$-compounds in microorganisms -9. The role of the glyoxylate cycle in protozoal glyconeogenesis. Biochem. F. 86, $462-468$.

KorNBERG H. L. (1963) The role of acetate in isocitrate lyase induction. Biochim. biophys. Acta 73, 517-519.

Kornberg H. L. (1964) Regulation of the glyoxylate cycle. Sixth int. Congr. Biochem. p. 678. New York.

KORNBERG H. L. \& ElsDen S. R. (1961) The metabolism of 2-carbon compounds by microorganisms. In Advances in Enzymology. Vol. 23, pp. 401-470. Interscience, New York.

KOROLY M. J. \& CONNER R. L. (1966) Factors influencing RNA metabolism in Tetrahymena pyriformis. F. Protozool. 13, Suppl. 13.

LEVY M. R. (1966) Interaction of environmental factors on activation of the glyoxylate bypass and glyconeogenesis in Tetrahymena. F. Protozool. 13, Suppl. 24.

LEVY M. R. (1967) Effects of inhibitors of RNA and protein synthesis on activation of glyconeogenesis in Tetrahymena. F. Cell Physiol. (In press.)

Levy M. R. \& Scherbaum O. H. (1965a) Glyconeogenesis in growing and non-growing cultures of Tetrahymena pyriformis. F. gen. Microbiol. 38, 221-230.

Levy M. R. \& Scherbaum O. H. (1965b) Induction of the glyoxylate cycle in Tetrahymena. Archs Biochem. Biophys. 109, 116-121.

Megraw R. E. \& BeERS R. J. (1964) Glyoxylate metabolism in growth and sporulation of Bacillus cereus. F. Bact. 87, 1087-1093.

Wegener W. S. \& Romano A. H. (1964) Control of isocitratase formation in Rhizopus nigricans. $\mathcal{F}$. Bact. 87, 156-161. 